\title{
PREVENTION \\ Polypills reduce CVD risk factors
}

Two separate trials have shown significant reductions in blood pressure (BP) and LDL-cholesterol (LDL-C) levels in individuals taking a 'polypill'. The investigators predict that these risk-factor modifications will reduce the incidence of cardiovascular events in the long term.

David Wald et al. from London, UK tested a polypill containing half-standard doses of three BP-lowering agents $(2.5 \mathrm{mg}$ amlodipine, $12.5 \mathrm{mg}$ hydrochlorothiazide, and $25 \mathrm{mg}$ losartan), and a standard $40 \mathrm{mg}$ dose of simvastatin. In total, 84 individuals with no history of cardiovascular disease (CVD), who were candidates for primary prevention purely on the basis of their age ( $\geq 50$ years), completed the trial. The double-blind study had a crossover design to maximize statistical power. Participants

Original articles Wald, D. S. et al. Randomized polypill crossover trial in people aged 50 and over. PLOS ONE 7, e41297 (2012) | Yusuf, S. et al. Comparison of risk factor reduction and tolerability of a full-dose polypill (with potassium) versus low-dose polypill (polycap) in individuals at high risk of cardiovascular diseases. The Second Indian Polycap Study (TIPS-2) investigators. Circ. Cardiovasc. Qual. Outcomes doi:10.1161/CIRCOUTCOMES.111.963637 took the polypill for 12 weeks and a placebo for 12 weeks in a random sequence. On the polypill, systolic and diastolic BPs and LDL-C levels were reduced by $17.9 \mathrm{mmHg}$, (12\%), $9.8 \mathrm{mmHg}(11 \%)$, and $1.4 \mathrm{mmol} / \mathrm{l}$ (54 mg/dl; 39\%), respectively. The drug was well tolerated, and no participant had a serious adverse event. The researchers predict that riskfactor reductions on this scale would decrease the incidence of ischemic heart disease events and stroke by $72 \%$ and $64 \%$, respectively.

In The Second Indian Polycap Study (TIPS-2), the polypill contained three BP-lowering drugs (50 $\mathrm{mg}$ atenolol, $12.5 \mathrm{mg}$ hydrochlorothiazide, and $5 \mathrm{mg}$ ramipril), $20 \mathrm{mg}$ simvastatin, and also $100 \mathrm{mg}$ aspirin, whose use in primary prevention is controversial. In total, 518 individuals eligible for secondary prevention were randomly allocated to receive either a single polypill, or two capsules of the polypill plus $\mathrm{K}^{+}$supplementation for 8 weeks. Compared with the single dose, the double ('full') dose reduced systolic and diastolic BPs and LDL-C levels by an additional $2.8 \mathrm{mmHg}$,

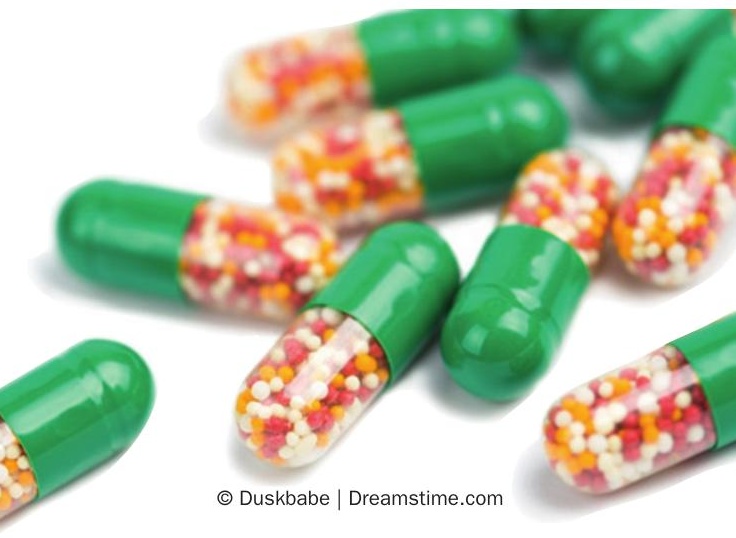

$1.7 \mathrm{mgHg}$, and $6.6 \mathrm{mg} / \mathrm{dl}$, respectively. Both doses were similarly well tolerated. The investigators anticipate that the full-dose regimen would reduce the risk of coronary heart disease by $75 \%$, and of stroke by $65 \%$.

The TIPS-3 investigators now plan to assess hard clinical end points over 5 years in a primary-prevention population of $>5,000$ individuals at moderate or high risk of, but without documented, CVD. In the $2 \times 2 \times 2$ factorial trial, the polypill will be tested without aspirin, with aspirin, and with vitamin $\mathrm{D}$. The measured outcomes will be CVD, CVD or cancer, and CVD or fractures in each trial arm, respectively.

Gregory B. Lim 